\title{
A Comparison of Surface Tension, Viscosity, and Density of Sn and Sn-Ag Alloys Using Different Measurement Techniques
}

\author{
Tomasz Gancarz • Zbigniew Moser • \\ Władysław Gąsior • Janusz Pstruś • Hani Henein
}

Received: 19 January 2010 / Accepted: 25 May 2011 / Published online: 11 June 2011 (C) The Author(s) 2011. This article is published with open access at Springerlink.com

\begin{abstract}
This work is aimed at comparing several methods for the measurement of physical properties for molten $\mathrm{Sn}$ and $\mathrm{Sn}-\mathrm{Ag}$ alloys, namely, surface tension, density, and viscosity. The method used for viscosity in this work is the modified capillary method. For surface tension and density, the data used for comparison were previously measured using the maximum bubble pressure method and the dilatometer technique, respectively, for four $\mathrm{Sn}-\mathrm{Ag}$ alloys having (3.8, 32, 55, and 68) at\% Ag. The results are compared with those obtained using a new method based on a fluid draining from a crucible under the influence of gravity, designated the Roach-Henein (RH) method. This new method enables the determination of these three physical properties in one set of measurements. Liquid Sn was used as well as two liquid Sn-Ag alloys having (3.8 and 34.6) at\% Ag with the RH method. It was determined that the RH method may be used to simultaneously obtain surface tension, viscosity, and density and that the errors associated with these measurements were similar to those obtained using traditional and separate techniques. Comparisons of the measured viscosity and surface tension to those predicted using thermodynamic models will also be presented. Finally a comparison of mixing model predictions with the experimentally measured alloy surface tension and viscosity is also presented.
\end{abstract}

Keywords Capillary method $\cdot$ Density $\cdot$ Dilatometer method $\cdot$ Maximum bubble-pressure method $\cdot$ Molten tin $\cdot$ Molten tin-silver alloys $\cdot$ RH method . Surface tension · Viscosity

T. Gancarz (凶) · Z. Moser · W. Gąsior · J. Pstruś Institute of Metallurgy and Materials Science, Polish Academy of Sciences, Krakow, Poland e-mail: nmgancar@imim-pan.krakow.pl

T. Gancarz $\cdot$ H. Henein

Department of Chemical and Materials Engineering, University of Alberta,

Edmonton, AB, Canada 


\section{List of Symbols}

A Molar surface area in a monolayer of species $i, \mathrm{~m}^{2}$

$A_{\mathrm{o}} \quad$ Pre-exponential in Eq. $39, \mathrm{mPa} \cdot \mathrm{s}$

$B \quad$ Starting liquid height $H_{\mathrm{s}}$ in the reservoir, m

$C_{\mathrm{m}} \quad$ Cumulative mass, $\mathrm{kg}$

$D(T)$ Diameter of lower container in CM method as a function of temperature $T, \mathrm{~m}$

$G \quad$ Free energy, $\mathrm{J} \cdot \mathrm{mol}^{-1}$

$G^{*} \quad$ Activation energy of the alloy, $\mathrm{J} \cdot \mathrm{mol}^{-1}$

$\Delta G^{\prime} \quad$ Change in activation energy, $\mathrm{J} \cdot \mathrm{mol}^{-1}$

$H_{\mathrm{s}} \quad$ Height of liquid at which measurement started, initial height, $\mathrm{m}$

$H_{\mathrm{f}} \quad$ Height of liquid at which measurement ended, final height, $\mathrm{m}$

$H_{\mathrm{m}} \quad$ Average height, $\mathrm{m}$

$H^{\mathrm{m}} \quad$ Molar enthalpy of mixing for the liquid alloy, $\mathrm{J} \cdot \mathrm{mol}^{-1}$

$L \quad$ Constant set to 1.091 for liquid metals assuming close-packed structures

$M \quad$ Molecular weight, $\mathrm{kg} \cdot \mathrm{mol}^{-1}$

$N_{0} \quad$ Avogadro's number, $\mathrm{mol}^{-1}$

$N_{\mathrm{s}} \quad$ Depth of capillary immersion at the beginning of measurement, $\mathrm{m}$

$N_{\mathrm{f}} \quad$ Depth of capillary immersion at the end of measurement, $\mathrm{m}$

$N_{\mathrm{m}} \quad$ Substitute depth of measurement, $\mathrm{m}$

$Q_{\text {exp }} \quad$ Experimental volumetric flow rate, $\mathrm{m}^{3} \cdot \mathrm{s}^{-1}$

$R \quad$ Universal gas constant, $\mathrm{J} \cdot \mathrm{mol}^{-1} \cdot \mathrm{K}^{-1}$

$S \quad$ Area under the curve between $H_{\mathrm{s}}$ and $H_{\mathrm{f}}, \mathrm{m} \cdot \mathrm{s}$

$T \quad$ Temperature, $\mathrm{K}$

$V \quad$ Volume of draining fluid, volume liquid, $\mathrm{m}^{3}$

$V_{i} \quad$ Molar volume of pure liquid $i, \mathrm{~m}^{3}$

$V_{s} \quad$ Volume of liquid drawn into the reservoir at the start of measurement, $\mathrm{m}^{3}$

$\Delta V^{\mathrm{E}} \quad$ Excess molar volume of alloy components

$W_{i, j} \quad$ Interaction coefficient for binary alloys

$X \quad$ Mole fraction, dimensionless

Z Coordination number

a Polynomial constant describing slope of the discharge coefficient curve, dimensionless

$b \quad$ Polynomial constant describing the $y$-intercept of the discharge coefficient curve, dimensionless

g Acceleration of gravity, $\mathrm{m} \cdot \mathrm{s}^{-2}$

$h \quad$ Planck's constant, J $\cdot \mathrm{s}$

$h_{\text {exp }} \quad$ Liquid head above a point of reference in RH method, $\mathrm{m}$

$l \quad$ Length of capillary, $\mathrm{m}$

$\Delta p \quad$ Pressure difference, $\mathrm{Pa}$

$r \quad$ Capillary radius in MC method, $\mathrm{m}$

$r_{\mathrm{c}} \quad$ Crucible radius, $\mathrm{m}$

$r_{\mathrm{o}} \quad$ Orifice radius in $\mathrm{RH}$ method, $\mathrm{m}$

$t \quad$ Time, $\mathrm{s}$

$u \quad$ Velocity, $\mathrm{m} \cdot \mathrm{s}^{-1}$ 
$\alpha \quad$ Constant

$\beta \quad$ Parameter corresponding to the ratio of the coordination number in the surface phase to that in the bulk phase $\left(Z^{\mathrm{S}} / Z^{\mathrm{B}}\right)$

$\eta \quad$ Viscosity, $\mathrm{mPa} \cdot \mathrm{s}$

$\eta_{\mathrm{H}} \quad$ Hagenbach correction for viscosity, $\mathrm{mPa} \cdot \mathrm{s}$

$\rho \quad$ Density, $\mathrm{kg} \cdot \mathrm{m}^{-3}$

$\sigma \quad$ Surface tension, $\mathrm{mN} \cdot \mathrm{m}^{-1}$

$\Phi$ Diameter of the bottom tank (crucible), $m$

Bo Bond number $\left(\frac{\rho g r_{0} h_{\exp }}{\sigma}\right)$, dimensionless

$C_{\mathrm{d}}$ Discharge coefficient, dimensionless

Fr Froude number $\left(\mathrm{Q}_{\exp }^{2} /\left(2 \pi g \mathrm{r}_{\mathrm{o}}^{3}\right)\right)$, dimensionless

$R e$ Reynolds number $\left(\frac{2 \rho Q_{\text {exp }}}{\pi r_{0} \eta}\right)$, dimensionless

\section{Superscripts}

B Bulk

E Excess

S Surface

ex Excess

\section{Subscripts}

Ag Silver

Sn Tin

\section{Introduction}

Over the past few years, efforts have been underway worldwide to eliminate lead from solders due to its toxicity. In proposing a new lead-free solder material, several physical properties must be evaluated including the liquid density, viscosity, and gas-liquid surface tension as a function of temperature.

In previous studies carried out by Moser et al. [1] on tin and liquid Sn-Ag alloys, the surface tension was measured using the maximum bubble-pressure method, the density was determined using the dilatometric technique, and the viscosity was reported using the capillary method that was previously used by Gąsior et al. [2] on $\mathrm{Pb}-\mathrm{Sn}$ alloys. Roach and Henein $[3,4]$ have developed a new method enabling the simultaneous measurement of surface tension, viscosity, and density in one run for fluids, herein referred to as the $\mathrm{RH}$ method. The method is based on a fluid exiting a crucible as a stream flowing under gravity. The model developed can be used to calculate these physical properties from only one experiment at a desired temperature. It was reported in Roach and Henein [4,5] that for liquid Al, the values of surface tension and density are reasonable, but the value of the viscosity differed from published values by nearly an order of magnitude. It was hypothesized that this may have been due to the fact that in the gravity flow method, the fluid flow is under turbulent conditions; therefore, the measured viscosity may be related to a turbulent dynamic viscosity. Hence, 
the values obtained were much lower than those reported by Rothwell [6] and by Kisun'ko et al. [7].

It was, therefore, decided to undertake parallel measurements of viscosity on tin and tin-silver alloys and to carry out a comparison of the surface tension and density with previously published measurements by Moser et al. [1]. Such a comparison of measurements will also provide a broader base of experimental results to compare against thermodynamic models of the physical properties of these alloys. This would also enable the extension of the data available in the SURDAT database [8].

\section{Viscosity Measurements: Modified Capillary (MC) Method}

The measurement of viscosity is based on the Hagen-Poisseulle (H-P) formula of capillary flow, which states that the volume of liquid flowing under laminar conditions out of a capillary is inversely proportional to the viscosity of the fluid and the capillary length but directly proportional to the pressure difference between the end of the capillary and the surface of the liquid in the reservoir as well as to the radius of the capillary raised to the fourth power:

$$
\frac{V}{t}=\frac{\pi \Delta p r^{4}}{8 \eta l}
$$

where $V$ is the liquid volume $\left(\mathrm{m}^{3}\right)$ that flows out during time $t(\mathrm{~s}), \Delta p$ is the pressure difference $(\mathrm{Pa}), r$ is the capillary radius $(\mathrm{m}), \eta$ is the viscosity $(\mathrm{mPa} \cdot \mathrm{s})$, and $l$ is the capillary length $(\mathrm{m})$. The viscosity can be calculated by rearranging Eq. 1 as shown in

$$
\eta=\frac{\pi r^{4} t}{8 l V} \Delta p
$$

Thus, if $V, t$, and $\Delta p$ are measured in an experiment, the Hagen-Poisseulle law in the form of Eq. 2 may be applied to obtain $\eta$. However, this only applies in the case when the liquid flows out from the capillary induced by a constant difference in pressure $\Delta p$ between the end of the capillary and the surface of the liquid in the reservoir. This is the case when the pressure is significantly higher than the hydrostatic pressure in the reservoir.

In the case of free outflow of liquid induced by a changing hydrostatic pressure (the lowering height of liquid column $H$ in the reservoir) both the volume, $V$, and pressure difference, $\Delta p$, are functions of time. Thus, $V=V(t), \Delta p=\Delta p(t)$, and $H=H(t)$ are all functions of time and Eq. 1 takes the following form:

$$
\frac{\mathrm{d} V(t)}{\mathrm{d} t}=\frac{\pi r^{4}}{8 \eta l} \Delta p_{1}(t)
$$


Fig. 1 Schematic of capillary flow method for measuring viscosity

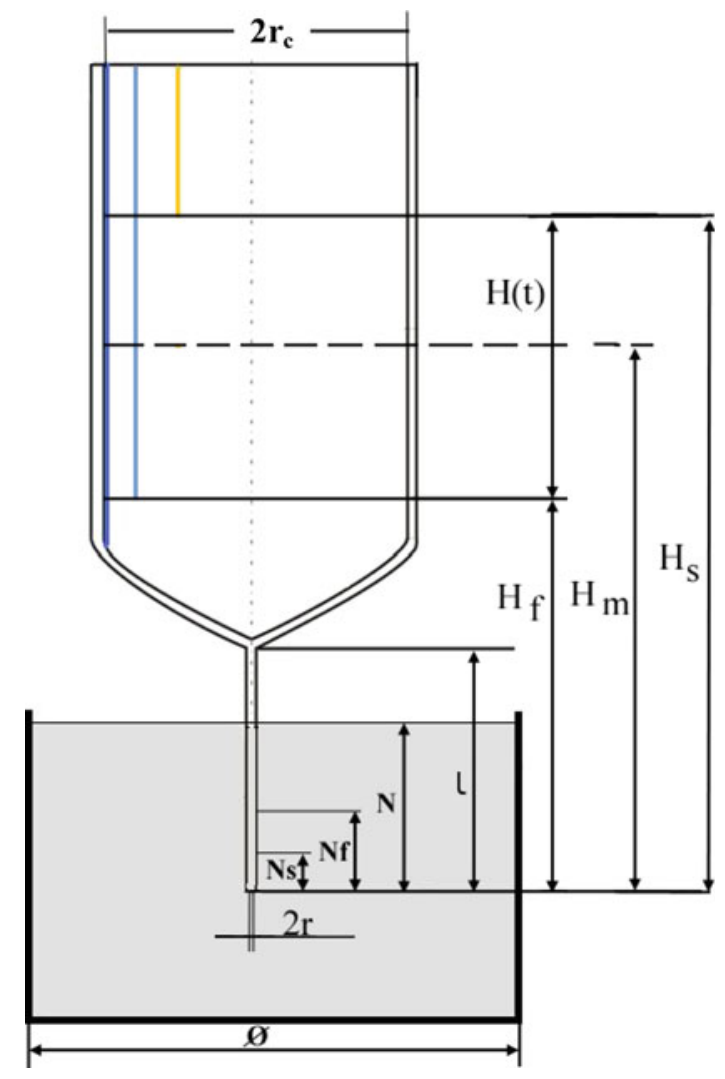

Since the hydrostatic pressure changes with the height of the liquid column, $H(t)$, in the reservoir (Fig. 1), Eq. 3 can be expressed in the following form:

$$
\frac{\pi R^{2} \mathrm{~d} H(t)}{\mathrm{d} t}=\frac{\pi r^{4} \rho g}{8 \eta l} H(t)
$$

Multiplying both sides of Eq. 4 by $\mathrm{d} t$ and dividing by $H(t), \pi$, and $R^{2}$, the following equation is obtained:

$$
\frac{\mathrm{d} H(t)}{H(t)}=\frac{\rho g r^{4}}{8 \eta l R^{2}} \mathrm{~d} t
$$

Defining $\alpha$, a constant, to be given by,

$$
\alpha=\frac{\rho g r^{4}}{8 \eta l R^{2}} .
$$


Eq. 5 can be re-written as

$$
\frac{\mathrm{d} H(t)}{H(t)}=\alpha \mathrm{d} t
$$

Integrating Eq. 7 over the limits $H=H_{\mathrm{s}}$ at $t=0$ and $H=H_{\mathrm{f}}$ at $t=t$ as shown in

$$
\int_{H_{\mathrm{S}}}^{H_{\mathrm{f}}} \frac{\mathrm{d} H(t)}{H(t)}=\int_{0}^{t} \alpha \mathrm{d} t
$$

yields

$$
\ln \frac{H_{\mathrm{f}}}{H_{\mathrm{s}}}=-\alpha t
$$

Rearranging Eq. 9,

$$
H_{\mathrm{f}}=H_{\mathrm{s}} \exp (-\alpha t)
$$

which can be used to calculate the height of the liquid in the reservoir after time $t$ (Fig. 1). Hence, after measuring the time of outflow of different volumes from the reservoir through the capillary, and assuming the parameter $\alpha$ of Eq. 10, the viscosity can be calculated from Eq. 6 .

The experiment is carried out in such a way, that during time, $t$, the outflow of a particular liquid volume is contained between heights $H_{\mathrm{s}}$ and $H_{\mathrm{f}}$ of the reservoir (Fig. 1). $H_{\mathrm{m}}$ is the average height of liquid represented by the change of height from $H_{\mathrm{s}}$ to $H_{\mathrm{f}}$ during time $t$ and can be calculated as an area $S$ under the curve given by Eq. 10 divided by the time of liquid outflow $t . S$, then, can be expressed as the following integral:

$$
S=\int_{0}^{t} H_{\mathrm{s}} \exp (-\alpha t) \mathrm{d} t=-\frac{H_{\mathrm{s}}}{\alpha} \mathrm{e}^{-\alpha t}-\frac{H_{\mathrm{s}}}{\alpha}
$$

After dividing by $t$, the average height, $H_{\mathrm{m}}$, is given by

$$
H_{\mathrm{m}}=\frac{S}{t}=\frac{H_{\mathrm{s}}}{\alpha t}\left(1-\mathrm{e}^{-\alpha t}\right)
$$

Incorporating Eqs. 9 and 10 into Eq. 12, the average height, $H_{\mathrm{m}}$, can be calculated from the initial height, $H_{\mathrm{s}}(t=0)$ and final height, $H_{\mathrm{f}}(t=t)$ as follows:

$$
H_{\mathrm{m}}=\frac{\left(H_{\mathrm{s}}-H_{\mathrm{f}}\right)}{\ln H_{\mathrm{s}}-\ln H_{\mathrm{f}}}
$$


Thus, the liquid volume $V$ that flows into the bottom under a changing hydrostatic pressure $\Delta p_{1}(t)$ may be written as

$$
\Delta p_{1}=\rho g \frac{\left(H_{\mathrm{s}}-H_{\mathrm{f}}\right)}{\ln H_{\mathrm{s}}-\ln H_{\mathrm{f}}}
$$

Taking into consideration the Hagenbach correction $\eta_{\mathrm{H}}$ [9] of the kinetic energy decrease of the liquid stream, which can be calculated from the following formula:

$$
\eta_{\mathrm{H}}=-\frac{V \rho}{8 \pi l t}
$$

and substituting Eq. 14 into Eq. 2, the following equation is obtained:

$$
\eta=\frac{\pi r^{4} \operatorname{t\rho g}}{8 l V}\left(\frac{\left(H_{\mathrm{s}}-H_{\mathrm{f}}\right)}{\left(\ln H_{\mathrm{s}}-\ln H_{\mathrm{f}}\right)}\right)-\frac{V \rho}{8 \pi l t}
$$

Thus, the viscosity of the liquid with density $\rho$ can be calculated. Note that from the experiment, the time, $t$, of the outflow of liquid volume, $V$ (contained between heights $H_{\mathrm{S}}$ and $H_{\mathrm{f}}$ ) through the capillary of radius, $r$, and length, $l$, must be measured.

Before starting the experiment, liquid is induced into the capillary and reservoir with the aid of a vacuum pump. Thus, the height of the liquid in the bottom tank will increase over the duration of the experiment. A correction of the pressure change $\Delta p_{2}(t)$ connected with the increase of liquid level in the bottom tank, into which the liquid from the reservoir flows must be incorporated into the model. The change of pressure $\Delta p_{2}(t)$ can be expressed according to a similar analysis presented above:

$$
\Delta p_{2}=\rho g \frac{N_{\mathrm{s}}-N_{\mathrm{f}}}{\ln N_{\mathrm{s}}-\ln N_{\mathrm{f}}}
$$

in which $N$ is the depth of capillary immersion before the suction of liquid up to the reservoir $(\mathrm{m}), N_{\mathrm{s}}=V_{\mathrm{s}} /\left(\pi \Phi^{2} / 4\right)$ is the depth of capillary immersion at the beginning of the measurement, e.g., after the suction of liquid of volume $V$ into the reservoir $(t=0)(\mathrm{m}), N_{\mathrm{f}}=N-N_{\mathrm{s}}$ is the depth of capillary immersion at the end of the experiment (m), i.e., after the flow of the liquid of volume $V, V_{\mathrm{s}}$ is the volume of liquid drawn into the reservoir $\left(\mathrm{m}^{3}\right), \Phi$ is the diameter of the bottom tank (crucible) (m) (Fig. 1),

$$
N(t)=N-N_{\mathrm{s}} \mathrm{e}^{-\beta t}
$$

where

$$
\beta=-1 / t \ln N_{\mathrm{s}} / N
$$

and

$$
\Delta p=\Delta p_{1}-\Delta p_{2}=\rho g\left(\frac{H_{\mathrm{S}}-H_{\mathrm{f}}}{\ln H_{\mathrm{S}}-\ln H_{\mathrm{f}}}-\frac{N_{\mathrm{s}}-N_{\mathrm{f}}}{\ln N_{\mathrm{S}}-\ln N_{\mathrm{f}}}\right)
$$


Thus, Eq. 20 represents the pressure change brought about by the level of liquid in the bottom tank changing due to drawing in of liquid from the capillary. This is valid provided that the volume of liquid leaving the reservoir of diameter $2 R$ and entering the bottom tank of diameter $\Phi$ are the same. Then the increase of the liquid level height in time $t$ may be expressed as a ratio of the volume of liquid which arrives into the bottom tank divided by its area. This leads to the relationship describing the change of immersion of the capillary (depth) in time $t$ of the outflow of liquid followed with the substitution with an average value $N_{\mathrm{m}}$ given by

$$
N_{\mathrm{m}}=N-\left(4 V_{\mathrm{s}} / \pi \Phi^{2}\right)+(2 R / \Phi)^{2}
$$

in which the depth $N_{\mathrm{s}}$ at the beginning of the measurement (m) is

$$
N_{\mathrm{s}}=N-4 V_{\mathrm{s}} / \pi \Phi^{2}
$$

$V_{\mathrm{s}}$ is the volume of liquid sucked into the reservoir at the start of the measurement $\left(\mathrm{m}^{3}\right), \Phi$ is the diameter of the bottom tank $(\mathrm{m})$, and $N_{\mathrm{m}}$ is the substitute depth of measurement (m). Finally, the pressure difference $\Delta p$, which is used in Eq. 1, can be calculated from the formula,

$$
\Delta p=\rho g\left(\frac{\Phi^{2}-4 r_{\mathrm{c}}^{2}}{\Phi^{2}} \frac{H_{\mathrm{s}}-H_{\mathrm{f}}}{\ln H_{\mathrm{s}}-\ln H_{\mathrm{f}}}-N+\frac{4 V_{\mathrm{s}}}{\pi \Phi^{2}}\right)
$$

The derived relations were tested by measuring the viscosity of carbon tetrachloride, methyl alcohol, and mercury. The measurements of liquid height changes in the reservoir after time $t$ are recorded and the results are shown in Fig. 2.

Fig. 2 Height of liquid in the capillary as a function of time for different liquids in the modified capillary (MC) method

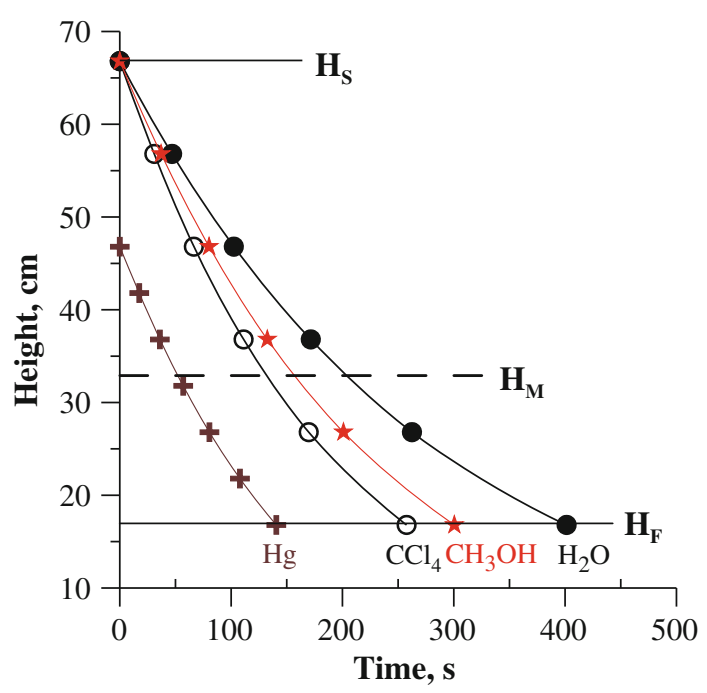


Fig. 3 Experimental results of viscosity versus literature data from Iida and Guthrie [10]

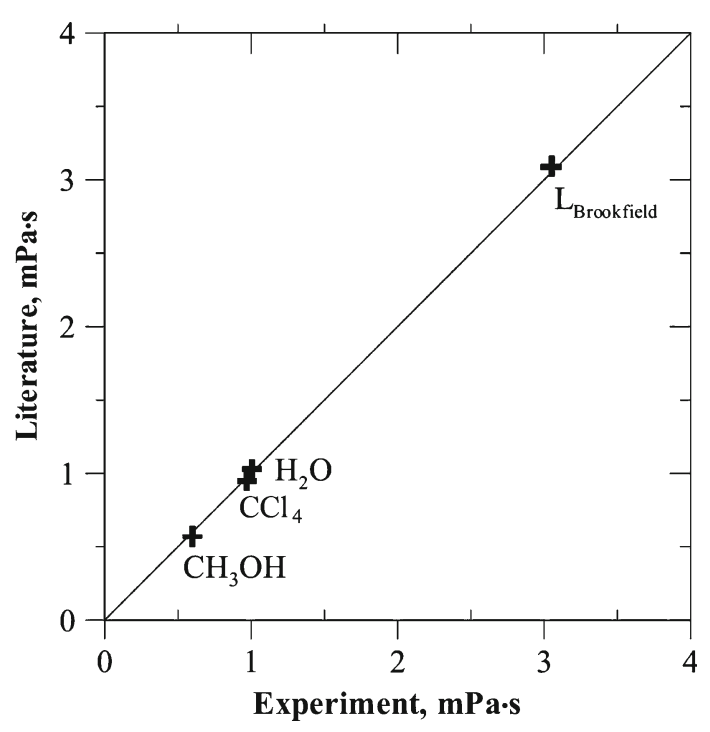

They fully confirm the above relation, which describes the liquid column height in the reservoir after time $t$, because each curve can be represented with an equation of the general form,

$$
H(t)=B \mathrm{e}^{-\alpha t}
$$

where $B$ is a starting liquid height $H_{\mathrm{s}}$ in the reservoir (Fig. 1). The viscosity can be determined using Eq. 6 and the measured $\alpha$ parameter. The measurement results for the mentioned earlier liquids, except for mercury, are presented in Fig. 3 (crosses) in reference to literature data (full line) [10]. Very good agreement between experimentally determined viscosity data and that published in the literature is seen in Fig. 3. Note that the derived relations apply only for the case of laminar flow of liquid through the capillary, i.e., for a Reynolds number $R e<2300$, influenced by hydrostatic pressure. The Reynolds number in the experiments oscillated in the range of 1600 to 2000 . For the case of mercury, the viscosity value was obtained with a high error because it had a much higher Reynolds number (turbulent outflow), and thus it was not included in the plot (Fig. 3).

Before the start of the experiment with a metal or alloy, it was placed in the bottom tank, a graphite crucible, above which the reservoir with the capillary of known dimensions was installed. Both elements were positioned in an alundum tube with a wound coil. Next, the device was hermetically sealed, air pumped out from the experimental space, and then it was back-filled with a protective atmosphere (mixture of argon and hydrogen). The protective atmosphere was passed through the apparatus during heating for several hours. In turn, using a micrometer screw, the lower crucible was lifted until it met the bottom of the capillary, which resulted in a fast increase of the gas pressure flowing out of the capillary. The capillary was then immersed to a specified depth, and the apparatus was thermally equilibrated for an hour. Next the 
Fig. 4 Viscosity of tin versus temperature using MC method compared with average data from Chhabra and Sheth [11] (dashed line), and with Gebhardt et al. [12] (solid line)
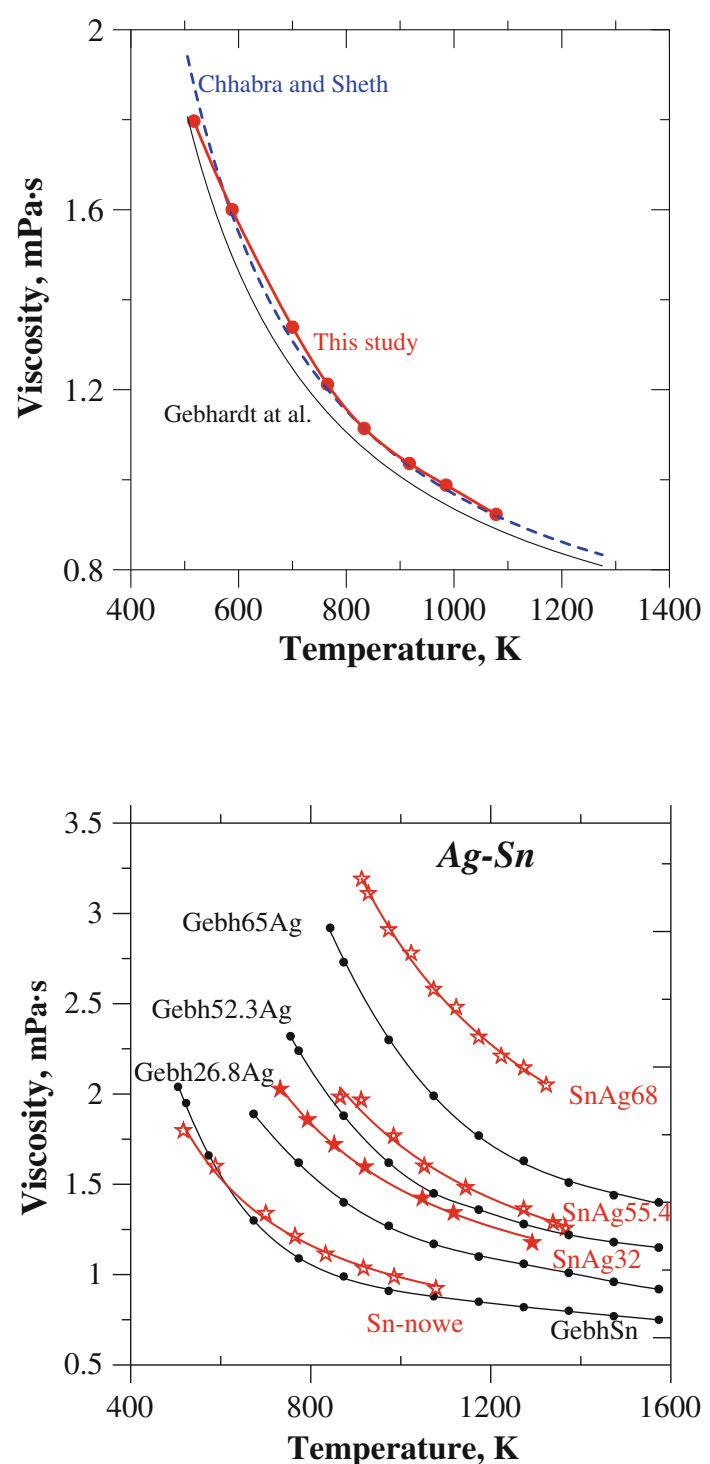

Fig. 5 Viscosity of liquid tin and tin-silver alloys versus temperature: solid circles Gebhardt et al. [12], stars MC method

liquid (alloy) from the crucible was sucked up to the reservoir, and the measurement of the outflow time of the determined volume of liquid through the capillary could begin.

Results of viscosity measurements as a function of temperature are plotted in Fig. 4 for $\mathrm{Sn}$ and in Fig. 5 for $\mathrm{Sn}-\mathrm{Ag}$ alloys. Excellent agreement with literature data is observed [11,12]. The viscosity as a function of temperature is expressed by an Arrhenius equation, and the results are shown in Table 1. 
Table 1 Temperature dependence of the viscosity of $\mathrm{Sn}$ and $\mathrm{Sn}-\mathrm{Ag}$ alloys with associated errors using the MC method

\begin{tabular}{|c|c|c|c|c|c|c|}
\hline \multirow[t]{2}{*}{$X_{\mathrm{Ag}}$} & \multicolumn{2}{|c|}{$\eta=A \mathrm{e}^{E /(R T)}$} & \multirow[t]{2}{*}{$\eta$ at $823 \mathrm{~K}(\mathrm{mPa} \cdot \mathrm{s})$} & \multirow[t]{2}{*}{$\partial \eta(\mathrm{mPa} \cdot \mathrm{s})$} & \multirow[t]{2}{*}{$\partial A$} & \multirow[t]{2}{*}{$\partial E$} \\
\hline & $A$ & $E$ & & & & \\
\hline $0, X_{\mathrm{Sn}}=1$ & 0.497713 & 5411.2 & 1.132 & \pm 0.044 & \pm 0.057 & \pm 341 \\
\hline 0.038 & 0.463408 & 6160.8 & 1.181 & \pm 0.072 & \pm 0.0466 & \pm 477 \\
\hline 0.32 & 0.587148 & 7314.4 & 1.783 & \pm 0.044 & \pm 0.0415 & \pm 339 \\
\hline 0.55 & 0.557895 & 8974.4 & 2.180 & \pm 0.123 & \pm 0.0989 & \pm 706 \\
\hline 0.68 & 0.769598 & 10398.4 & 3.734 & \pm 0.089 & \pm 0.0469 & \pm 350 \\
\hline
\end{tabular}

\section{Surface Tension, Density, and Viscosity Studies Using the RH Method}

Roach and Henein [3-5] developed a new method for fluids to simultaneously measure the surface tension, viscosity, and density in one experiment. The RH method is based on a fluid exiting a crucible as a stream, flowing under gravity. It was reported that for liquid $\mathrm{Al}$ the values of surface tension and density were reasonable [4], but the values of viscosity differed from published values (Rothwell [6] and Kisun'ko [7]) by nearly an order of magnitude. It was hypothesized that this may be due to the fact that since in the gravity flow method, fluid is under turbulent conditions, the Reynolds numbers are in excess of 4000, contrary to viscous flow of the H-P law.

The essential part of the experimental apparatus for measurements of surface tension, viscosity, and density are described in detail in Roach and Henein [4]. It consists of a draining vessel depicting free gravitational flow of a fluid through an orifice placed in the bottom of the crucible (Fig. 6).

Fig. 6 Schematic of draining vessel system depicting flow rate of a fluid through an orifice placed at the bottom, the $\mathrm{RH}$ method

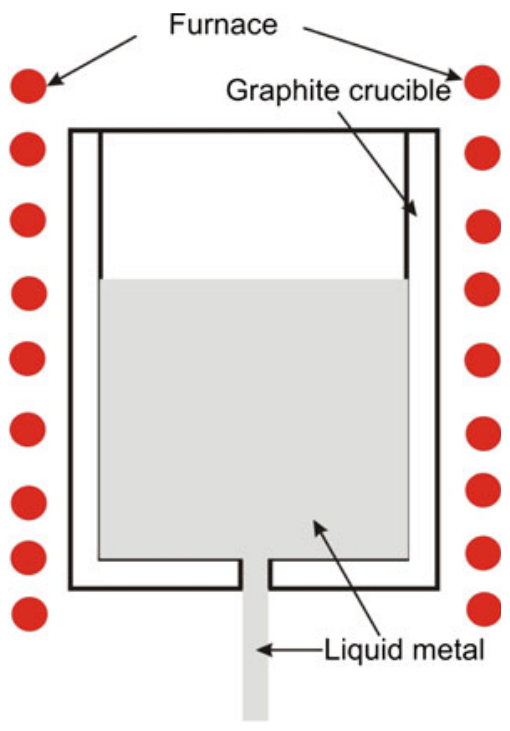


The derivation proposed by Roach and Henein [4] is similar to the traditional Bernoulli formulation, except that an additional term is included because the pressure induced from the surface tension is quantified in the model. Therefore, the Froude and Bond numbers are analyzed. The Froude number represents the ratio of the inertial force of the stream to the potential force of the liquid head above the orifice discharge. The Bond number represents the ratio of the potential force to the surface force of the stream exiting the orifice. The following relation should be satisfied:

$$
F r+1 / B o=1
$$

Starting from the known radius of the orifice, $\mathrm{r}_{0}, 0.001 \mathrm{~m}$, the height for water varied from $0.08 \mathrm{~m}$ to $0.05 \mathrm{~m}$, while for tin, it ranged from $0.05 \mathrm{~m}$ to $0.02 \mathrm{~m}$ which satisfy the relation between $\mathrm{Fr}$ and $\mathrm{Bo}$ [3-5]. The different heights for water and tin are due to differences in their densities and surface tensions.

Using liquids of known physical properties and an orifice of a given diameter to be used with melts, a calibration of $C_{\mathrm{d}}$ versus $R e$ was developed. Water and tin were used as calibration fluids with their physical properties taken from the literature [13-16]. During the flow, the mass was measured as a function of time using a load cell. The cumulative mass $C_{\mathrm{m}}$ versus time curve for tin and water is obtained and fitted with a third-order polynomial. An example of the polynomial for tin at $723 \mathrm{~K}$ is given by the following equation and a sample result is shown in Fig. 7:

$$
C_{\mathrm{m}}=-\left(6 \times 10^{-8}\right) t^{3}-\left(3 \times 10^{-5}\right) t^{2}+0.12 t+0.011
$$

Knowing $C_{\mathrm{m}}$, the experimental volumetric flow rate, $Q_{\exp }\left(\mathrm{m}^{3} \cdot \mathrm{s}^{-1}\right)$ can be determined,

$$
Q_{\exp }=\frac{1}{\rho} \frac{\partial C_{\mathrm{m}}}{\partial t}
$$

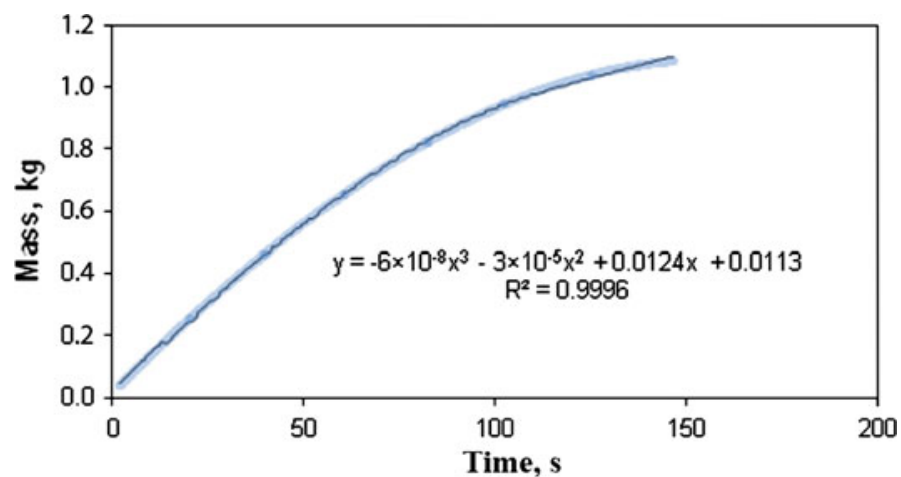

Fig. 7 Cumulative mass $C_{\mathrm{m}}$ as a function of time for tin at $723 \mathrm{~K}$ through a $0.001 \mathrm{~m}$ radius of the orifice 
The discharge coefficient, $C_{\mathrm{d}}$, of the orifice which characterizes friction losses in the orifice, is determined and is defined as the ratio between the experimental flow rate $Q_{\exp }$ and theoretical flow rate $Q_{\text {theor }}\left(\mathrm{m}^{3} \cdot \mathrm{s}^{-1}\right)$. It is given by

$$
C_{\mathrm{d}}=\frac{Q_{\exp }}{\pi r_{0}^{2} \sqrt{2 g\left(h_{\exp }-\frac{\sigma}{\rho g r_{0}}\right)}}
$$

$Q_{\text {exp }}$ is also used to calculate the Reynolds number $(R e)$. The Reynolds number is used in characterizing the inertial forces relative to viscous losses in the orifice, and is calculated using the relation,

$$
R e_{\exp }=\frac{2 \rho Q_{\exp }}{\pi r_{0} \eta}
$$

Finally, the relation of $C_{\mathrm{d}}$ versus $R e$ is plotted and is shown in Fig. 8. Six different calibration curves are shown in Fig. 8. Four of them are for tin at varying temperatures and two for water also at different temperatures. Clearly, the friction losses $\left(C_{\mathrm{d}}\right)$ in the orifice are nearly the same in all cases. For materials of unknown properties, the relation between $C_{\mathrm{d}}$ and $R e$ will be used to determine the physical properties. This will be discussed later.

A third-order polynomial was used to fit all six data sets and is expressed as

$$
C_{\mathrm{d}}=2 \times 10^{-12} R e^{3}-4 \times 10^{-8} R e^{2}+0.0003 R e-0.0114
$$

In this work only the data with $R e>4000$ were used in determining the physical properties of tin and $\mathrm{Sn}-\mathrm{Ag}$ alloys. A linear fit to the $C_{\mathrm{d}}$ versus $R e$ calibration data for $R e>4000$ is therefore used and is given by

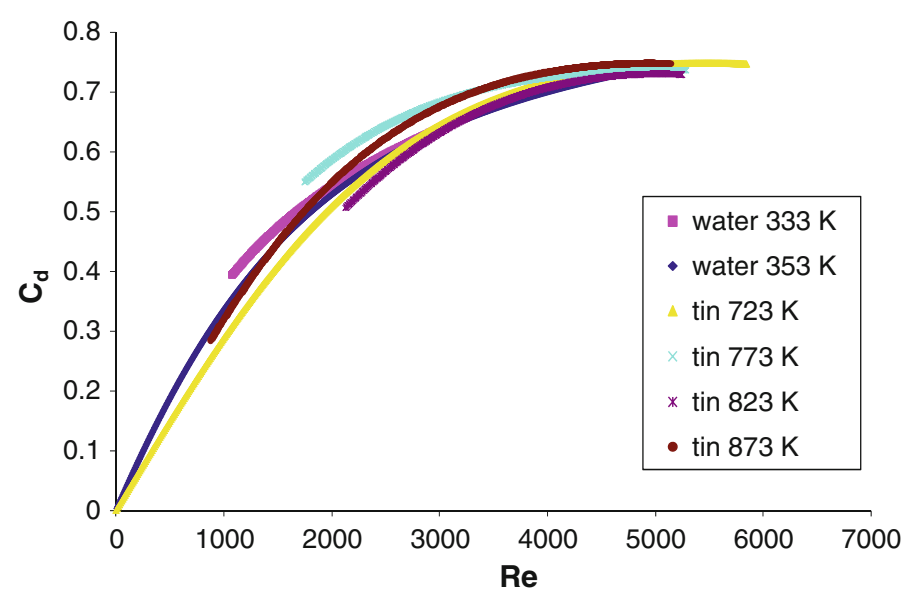

Fig. 8 Calibration for a $0.002 \mathrm{~m}$ diameter orifice and height of $0.06 \mathrm{~m}$ to $0.08 \mathrm{~m}$ using water at $333 \mathrm{~K}$ and $353 \mathrm{~K}$, and tin for a height of $0.004 \mathrm{~m}$ to $0.06 \mathrm{~m}$ at $723 \mathrm{~K}, 773 \mathrm{~K}, 823 \mathrm{~K}$, and $873 \mathrm{~K}$ 


$$
C_{\mathrm{d}}=5 \times 10^{-5} R e+0.6844
$$

Using data determined in the calibration procedure along with Eq. 28, the calculations of the surface tension, density, and viscosity were undertaken by an iterative method.

\subsection{Surface Tension}

The method for determining the physical properties of Sn and $\mathrm{Sn}-\mathrm{Ag}$ alloys is based on the following equation:

$$
\sigma=\rho g r_{0}\left[h_{\exp }-\frac{1}{2 g}\left(\frac{Q_{\exp }}{(a R e+b) \pi r_{0}^{2}}\right)^{2}\right]
$$

by means of an iterative method with initial values of the density of tin with coefficients $a$ and $b$ taken from Eq. 31. In this section, the results obtained for the surface tension will be discussed. Subsequently, the results for the density and viscosity will be presented.

The results for tin are shown in Fig. 9, and those for Sn-Ag alloys for the surface tension as a function of temperature are presented in Table 2 and plotted in Fig. 10. With an increase in temperature, the surface tension of liquid Sn decreases linearly. The results show very good agreement with the values calculated with the equation (A) recommended by Keene [17], over the whole range of temperature. Also, good agreement is observed between our data and the results of Fiori from Ref. [14] at low

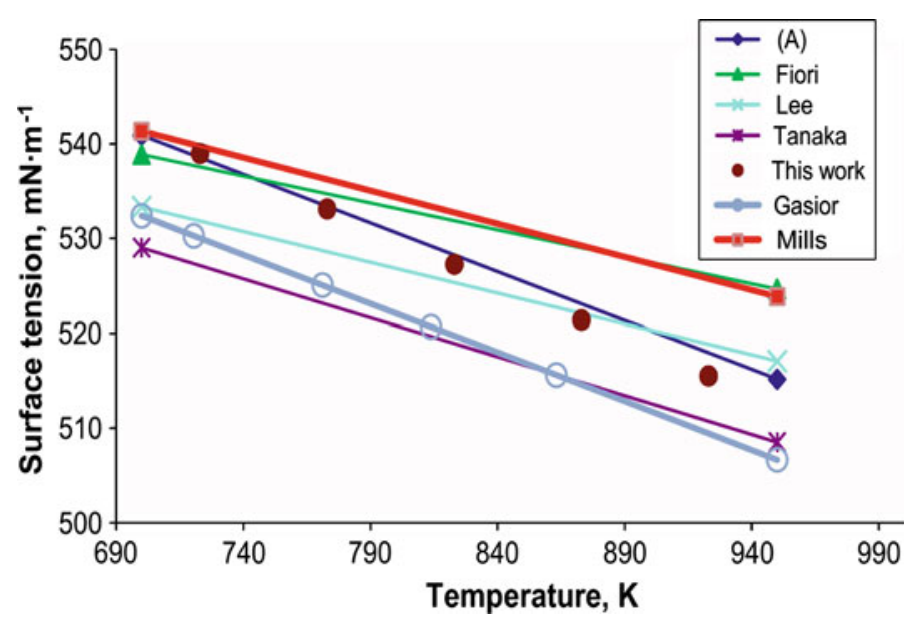

Fig. 9 Surface tension of pure tin as a function of temperature compared with literature data: triangles Fiori [13], stars Tanaka [13], diamonds (A) using $\sigma=613.6-0.103 T$ Keene [17], squares Mills and Su [13], cross Lee et al. [18], open circles Gasior et al. [2], and closed circles this work (RH method) 
Table 2 Relations for surface tension of $\mathrm{Sn}$ and $\mathrm{Sn}-\mathrm{Ag}$ alloys with errors using the RH method

\begin{tabular}{|c|c|c|c|c|c|c|}
\hline \multirow[t]{2}{*}{$X_{\text {Sn }}$} & \multicolumn{2}{|c|}{$\sigma=A+B T$} & \multirow[t]{2}{*}{$\sigma$ at $823 \mathrm{~K}\left(\mathrm{mN} \cdot \mathrm{m}^{-1}\right)$} & \multirow[t]{2}{*}{$\partial \sigma\left(\mathrm{mN} \cdot \mathrm{m}^{-1}\right)$} & \multirow[t]{2}{*}{$\partial A$} & \multirow[t]{2}{*}{$\partial B$} \\
\hline & $A$ & $B$ & & & & \\
\hline 1.000 & 623.7 & -0.1173 & 527.4 & \pm 8.0 & \pm 41.6 & \pm 0.0504 \\
\hline 0.962 & 625.5 & -0.1100 & 534.9 & \pm 10.5 & \pm 20.2 & \pm 0.0261 \\
\hline 0.654 & 638.5 & -0.0720 & 579.2 & \pm 11.3 & \pm 18.4 & \pm 0.0193 \\
\hline
\end{tabular}

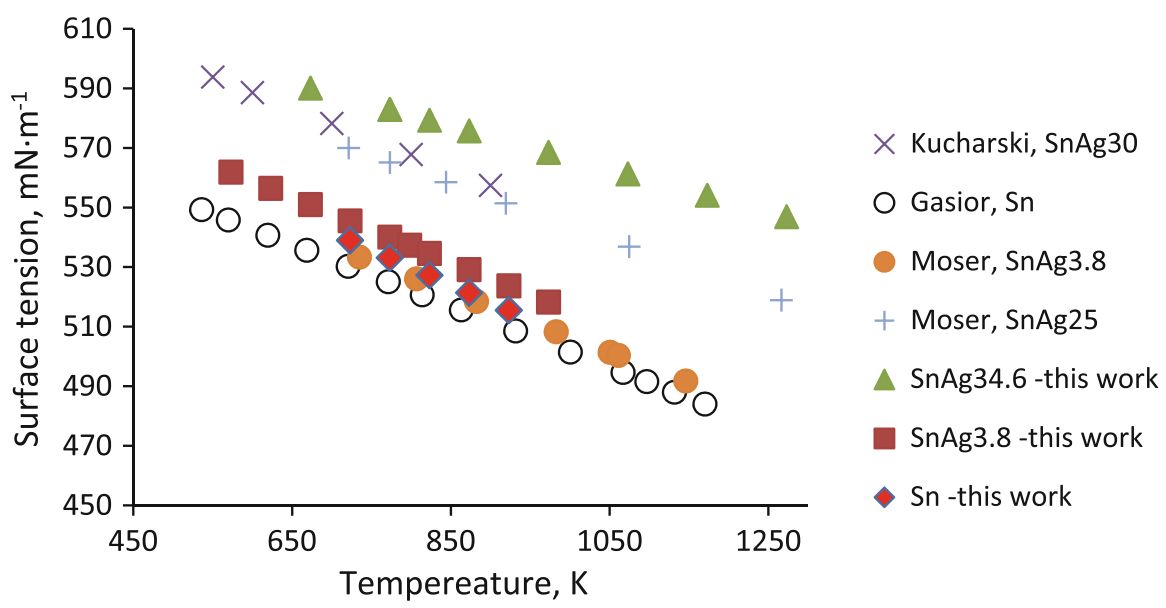

Fig. 10 Surface tension of Sn and $\mathrm{Sn}-\mathrm{Ag}$ alloys as a function of temperature using the RH method compared with literature data of Gasior et al. [2], Moser et al. [1], and Kucharski and Fima [19]

temperature, and the results from Lee et al. [18] at high temperature. The results of Gąsior et al. [2] and Tanaka from Ref. [14] are slightly lower compared with our data.

The results for $\mathrm{Sn}$ and $\mathrm{Sn}-\mathrm{Ag}$ alloys using the RH method are plotted in Fig. 10. With increasing temperature, the surface tension of liquid $\mathrm{Sn}$ and $\mathrm{Sn}-\mathrm{Ag}$ alloys decreases linearly. One can see that the surface-tension temperature coefficients $(\mathrm{d} \sigma / \mathrm{d} T)$ for eutectic compositions determined by the RH method and by Moser et al. [1] are very similar. From Fig. 10 it is shown that good agreement is observed between the RH method results and literature data [1,2,19]; also evident in Fig. 10 is that the surface tension increases with the concentration of silver.

\subsection{Modeling of the Surface Tension}

Surface-tension data for seven Ag-Sn alloys from a previous study [1] were interpreted by the Butler model [20] using the following equation:

$$
\begin{aligned}
\sigma & =\sigma_{\mathrm{Ag}}+\frac{R T}{A_{\mathrm{Ag}}} \ln \frac{\left(1-x_{\mathrm{Sn}}^{\mathrm{S}}\right)}{\left(1-x_{\mathrm{Sn}}^{\mathrm{B}}\right)}+\frac{1}{A_{\mathrm{Ag}}}\left[{ }^{\mathrm{ex}} G_{\mathrm{Ag}}^{\mathrm{S}}\left(T, X_{\mathrm{Sn}}^{\mathrm{S}}\right)-{ }^{\mathrm{ex}} G_{\mathrm{Sn}}^{\mathrm{B}}\left(T, X_{\mathrm{Sn}}^{\mathrm{B}}\right)\right] \\
& =\sigma_{\mathrm{Sn}}+\frac{R T}{A_{\mathrm{Sn}}} \ln \left(\frac{X_{\mathrm{Sn}}^{\mathrm{S}}}{X_{\mathrm{Sn}}^{\mathrm{B}}}\right)+\frac{1}{A_{\mathrm{Sn}}}\left[G_{\mathrm{Sn}}^{\mathrm{E}, \mathrm{S}}\left(T, X_{\mathrm{Sn}}^{\mathrm{S}}\right)-G_{\mathrm{Sn}}^{\mathrm{E}, \mathrm{B}}\left(T, X_{\mathrm{Sn}}^{\mathrm{B}}\right)\right]
\end{aligned}
$$


where $R$ is the gas constant in $\mathrm{J} \cdot \mathrm{mol}^{-1} \cdot \mathrm{K}^{-1} ; T$ is the temperature in $\mathrm{K} ; \sigma_{\mathrm{Ag}}$ and $\sigma_{\mathrm{Sn}}$ are the surface tensions of pure silver and tin in $\mathrm{mN} \cdot \mathrm{m}^{-1} ; A_{\mathrm{i}}$ is the molar surface area in a monolayer of pure liquid $i(i=\mathrm{Ag}$ or $\mathrm{Sn})$ in $\mathrm{m}^{2}$; and $X_{\mathrm{Sn}}^{S}$ and $X_{\mathrm{Sn}}^{B}$ are the mole fractions of $\mathrm{Sn}$ in the surface and the bulk phase, respectively. The molar surface area $A_{i}$ can be obtained from the relation,

$$
A_{i}=L N_{0}^{1 / 3} V_{0}^{2 / 3}
$$

where $N_{0}$ is the Avogadro number; $V_{i}$ is the molar volume of pure liquid $i\left(\mathrm{~m}^{3}\right) ; L$ is usually set to 1.091 for liquid metals assuming close-packed structures; $G_{i}^{\mathrm{E}, \mathrm{S}}\left(\mathrm{T}, X_{\mathrm{i}}\right)$ and $G_{i}^{\mathrm{E}, \mathrm{B}}\left(T, X_{i}\right)$ are the partial excess Gibbs energies of component $i$ in the surface and bulk phases as function of $T$ and $X_{i}$, with $X_{i}$ being the mole fraction of component $i\left(\mathrm{~J} \cdot \mathrm{mol}^{-1}\right)$. The following equation provides a relation for the excess Gibbs energy in the bulk and surface phases:

$$
G_{i}^{\mathrm{E}, \mathrm{S}}\left(T, X_{i}^{\mathrm{S}}\right)=\beta G_{i}^{\mathrm{E}, \mathrm{B}}\left(T, X_{i}^{\mathrm{S}}\right)
$$

where $\beta$ is a parameter corresponding to the ratio of the coordination number in the surface phase to that in the bulk phase $Z^{\mathrm{S}} / Z^{\mathrm{B}}$, and it is assumed that $\beta=0.83$ for liquid metals [21].

The surface tension of liquid Ag-Sn alloys was calculated using the values of the partial excess Gibbs energies of Ag and Sn from optimized thermodynamic parameters [22]. For calculations of molar volumes of Ag-Sn alloys, the densities determined from this study were used with densities for pure Ag from [23] and for pure tin from [24].

The excess free energy was calculated using a binary model. This model for binary solutions is given by

$$
G^{\mathrm{ex}}=\sum_{i=1}^{2} \sum_{j=2}^{3} X_{i} X_{j} W_{i, j}
$$

where $W_{i, j}$ is the interaction coefficient for binary alloys which is obtained from the database of thermodynamic properties by ADAMIS [25]:

$$
\begin{aligned}
W_{\mathrm{Ag}, \mathrm{Sn}}= & (-4902.5-4.30532 T)+(-16474+3.12507 T)\left(X_{\mathrm{Ag}}-X_{\mathrm{Sn}}\right) \\
& -7298.6\left(X_{\mathrm{Ag}}-X_{\mathrm{Sn}}\right)^{2}
\end{aligned}
$$

$X_{i}$ 's are the mole fractions. Surface-tension data for pure liquid Sn and Ag were taken from [26] and [27]. Figure 11 illustrates a comparison between the results of calculations (lines) and the experimental data (circle, square) for respective compositions. The surface tension calculated from the model decreases with increasing temperature and increases with increasing Sn concentration, which is in accordance with experimental results. Good agreement is observed between calculated and all experimental data. 
Fig. 11 Surface tension of tin and $\mathrm{Sn}-\mathrm{Ag}$ alloys as a function of temperature compared with the Butler model: solid line Butler model, circles Gasior et al. [2], squares this work (RH method)

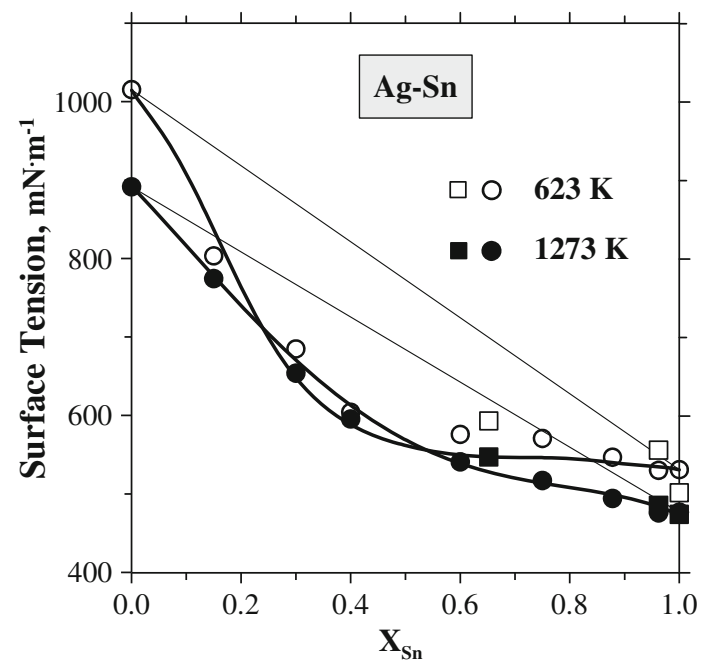

\subsection{Density}

The results for the density of tin and $\mathrm{Sn}-\mathrm{Ag}$ alloys that were calculated simultaneously with the surface tension using Eq. 32 and associated errors are reported in Table 3. The maximum error in the data is less than $2.5 \%$.

Data from Table 3 for tin were used to prepare Fig. 12. With increasing temperature, the density of liquid Sn decreases linearly. The results obtained show very good agreement with the results of Berthou and Tougas [28] and Pstrus [29] over the whole range of temperature. Also, good agreement is observed between the data obtained using the RH method and the results of Smithells [30] and Kucharski [24].

The $\mathrm{Sn}-\mathrm{Ag}$ alloy density is also shown in Fig. 13 together with a comparison with other literature data. The results in Fig. 13 indicate that with increasing temperature, the density of liquid $\mathrm{Sn}$ and $\mathrm{Sn}-\mathrm{Ag}$ alloys decreases linearly. One can see that the density temperature coefficients $(\mathrm{d} \rho / \mathrm{d} T)$ for eutectic compositions determined by using the RH method and by Moser et al. [1] and Kaban et al. [31] are very similar. From Fig. 13 it is noted that good agreement is observed between data obtained using the RH method and literature data; and also, the density increases with increasing concentration of silver.

Table 3 Relations for density of Sn and Sn-Ag alloys with errors using the RH method

\begin{tabular}{|c|c|c|c|c|c|c|}
\hline \multirow[t]{2}{*}{$X_{\mathrm{Sn}}$} & \multicolumn{2}{|c|}{$\rho=A+B T$} & \multirow[t]{2}{*}{$\rho$ at $823 \mathrm{~K}\left(\mathrm{~kg} \cdot \mathrm{m}^{-3}\right)$} & \multirow[t]{2}{*}{$\partial \rho\left(\mathrm{kg} \cdot \mathrm{m}^{-3}\right)$} & \multirow[t]{2}{*}{$\partial A$} & \multirow[t]{2}{*}{$\partial B$} \\
\hline & $A$ & $B$ & & & & \\
\hline 1.000 & 7.2986 & -0.000648 & 6.765 & \pm 0.018 & \pm 0.092 & \pm 0.000112 \\
\hline 0.962 & 7.3793 & -0.000591 & 6.893 & \pm 0.030 & \pm 0.058 & \pm 0.000075 \\
\hline 0.654 & 8.6433 & -0.001094 & 7.743 & \pm 0.193 & \pm 0.314 & \pm 0.000330 \\
\hline
\end{tabular}




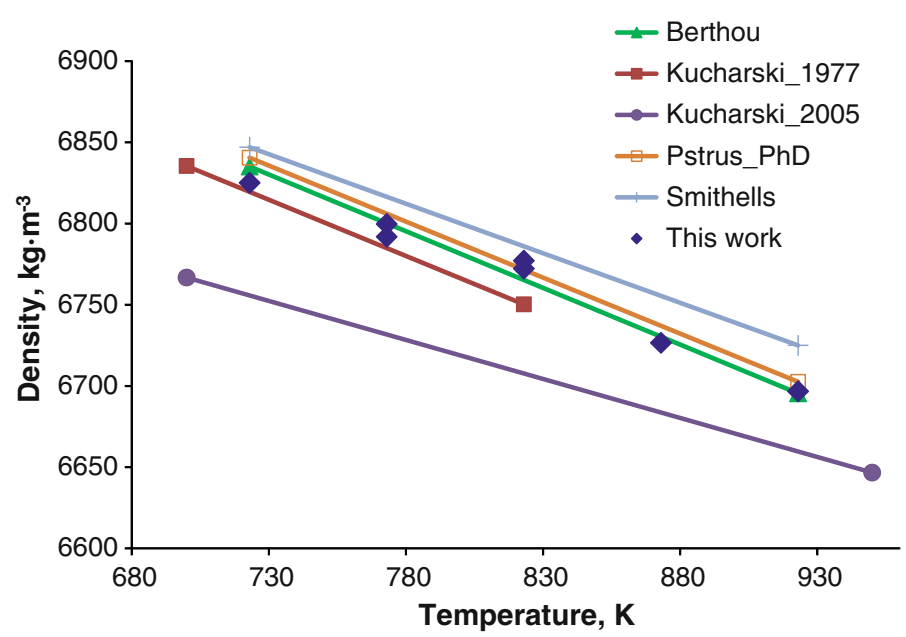

Fig. 12 Density of pure tin as a function of temperature compared with literature data of Kucharski_1977 Kucharski [24], Kucharski_2005 Kucharski and Fima [19], Berthou Berthou and Tougas [28], Pstrus_PhD Pstruś [29], Smithells Smithells [30], diamonds this work (RH method)

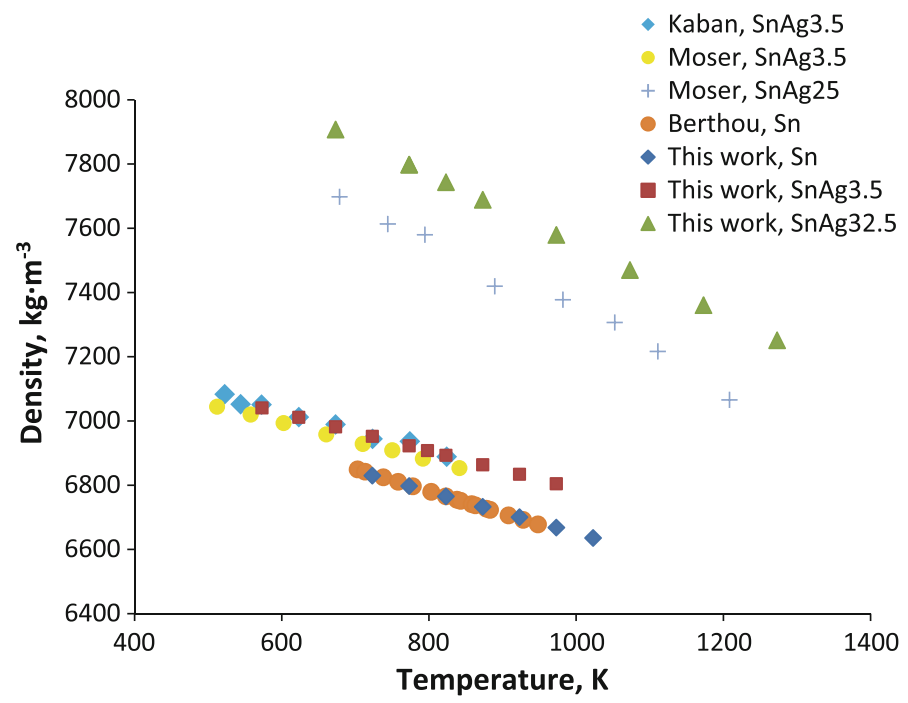

Fig. 13 Density of $\mathrm{Sn}$ and $\mathrm{Sn}-\mathrm{Ag}$ alloys as a function of temperature using the $\mathrm{RH}$ method compared with literature data of Moser et al. [1], Kaban et al. [31], and Berthou and Tougas [28]

\subsection{Viscosity}

Finally the values of the viscosity of $\mathrm{Sn}$ and $\mathrm{Sn}-\mathrm{Ag}$ alloys were also calculated from Eq. 32 which was used to determine the density and surface tension using the RH method. They are presented in Table 4 and used in plotting Fig. 14. Data from Gebhardt et al. [12] are also plotted in Fig. 14. 
Table 4 Relations for viscosity of Sn and Sn-Ag alloys with errors using the RH method

\begin{tabular}{|c|c|c|c|c|c|c|}
\hline \multirow[t]{2}{*}{$X_{\text {Sn }}$} & \multicolumn{2}{|c|}{$\eta=A \mathrm{e}^{E /(R T)}$} & \multirow[t]{2}{*}{$\eta$ at $823 \mathrm{~K}(\mathrm{mPa} \cdot \mathrm{s})$} & \multirow[t]{2}{*}{$\partial \eta(\mathrm{mPa} \cdot \mathrm{s})$} & \multirow[t]{2}{*}{$\partial A$} & \multirow[t]{2}{*}{$\partial E$} \\
\hline & $A$ & $E$ & & & & \\
\hline 1.000 & 0.3847256 & 7511.66 & 1.153 & \pm 0.013 & \pm 0.059 & \pm 348 \\
\hline 0.962 & 0.3935107 & 7791.64 & 1.229 & \pm 0.110 & \pm 0.067 & \pm 647 \\
\hline 0.654 & 0.5799891 & 7821.34 & 1.820 & \pm 0.097 & \pm 0.079 & \pm 493 \\
\hline
\end{tabular}

Fig. 14 Viscosity of tin and $\mathrm{Sn}-\mathrm{Ag}$ alloys as a function of temperature using the $\mathrm{RH}$ method (diamonds) compared with points from Gebhardt et al. [12]

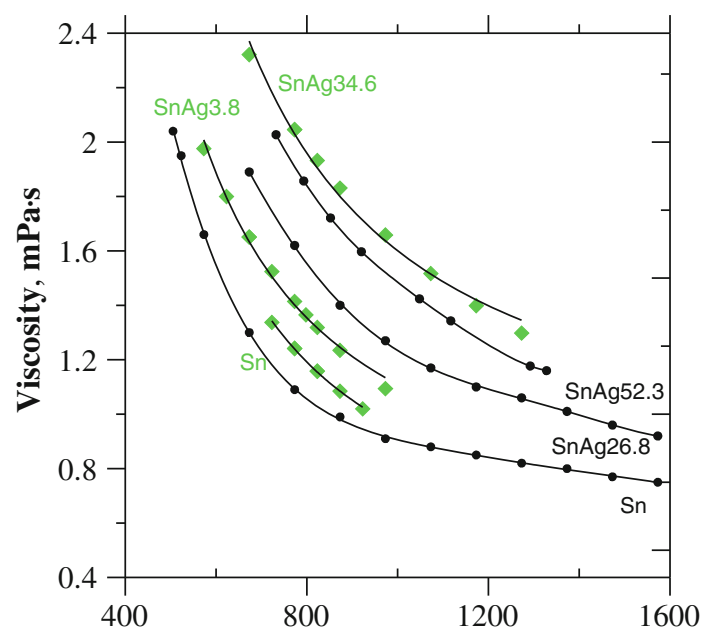

Temperature, $\mathbf{K}$

The resulting viscosity data were interpreted using an Arrhenius equation. With increasing temperature, the viscosity of liquid $\mathrm{Sn}$ and $\mathrm{Sn}-\mathrm{Ag}$ alloys decreases logarithmically. One can see that the viscosity temperature coefficients $(\mathrm{d} \eta / \mathrm{d} T)$ for $\mathrm{Sn}$ and for $\mathrm{Sn}-\mathrm{Ag}$ compositions determined by the RH method and by Gebhardt et al. [12] are very similar. The results for viscosity measurements for $\mathrm{Sn}$ and $\mathrm{Sn}-\mathrm{Ag}$ alloys using the MC and RH methods are shown in Fig. 15 and Table 4. The results from both methods are clearly in agreement with each other.

\subsection{Modeling of Metal Alloy Viscosity Based on Thermodynamic and Physical Properties}

The scientific literature provides models for predicting the viscosity of liquid alloys using thermodynamic properties such as the excess molar free energy or the molar enthalpy of mixing as well as, in some cases, using physical properties such as the viscosity of components, density, or molar volume of alloys, atomic masses and radii. The earliest and simplest equation (Eq. 40) was derived by Moelwyn-Hughes and reported in [32]: 
Fig. 15 Viscosity as a function of temperature from MC method (open and filled stars), from RH method (diamonds) and from Gasior et al. [2] (crosses)

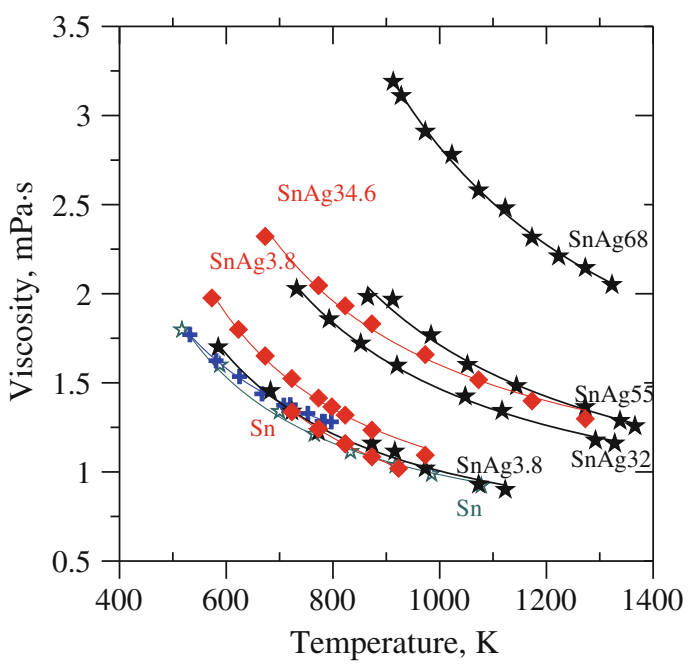

$\eta=\left(\eta_{1} X_{1}+\eta_{2} X_{2}\right)\left(1-2 \frac{H^{\mathrm{m}}}{R T}\right)$

For a binary system, $\eta, \eta_{1}$, and $\eta_{2}$ denote the viscosity of an alloy and its components; $X_{1}, X_{2}$ represent the molar fractions of the components; $R$ is the gas constant; $T$ is the temperature, and $H^{\mathrm{m}}$ is the molar enthalpy of mixing for the liquid alloy. In the case of multicomponent alloys, the authors have applied a simple extension of Eq. 38 taking the second part of the expression as a constant, while the first relation was substituted with a sum of three products $\eta_{i} X_{i}$.

In 1987, Sichen et al. [33] proposed the following equations, which comprised the thermodynamic properties of liquid solutions, their densities, activation energies, and viscosities of components, to calculate the viscosity of multicomponent solutions:

$$
\begin{aligned}
\eta & =A_{\mathrm{o}} \exp \left(\frac{G^{*}}{R T}\right) \\
A_{\mathrm{o}} & =\frac{h N_{0} \rho}{M} \\
G^{*} & =\sum_{i=1}^{n} X_{i} G_{i}^{*}+R T \sum_{i=1}^{n-1} \sum_{k=i+1}^{n} X_{i} X_{k}+\Delta G^{\prime}
\end{aligned}
$$

where $G^{*}$ denotes the activation energy of the alloy, $\Delta G^{\prime}$ is the change of activation energy, $T$ is the temperature, $G_{1}^{*}$ and $G_{2}^{*}$ are activation energies of the components, $R$ is the gas constant, $\rho$ is the alloy density, $N_{0}$ is the Avogadro number, $h$ is Planck's constant, and $M$ is the atomic mass of alloy components. 
In the same year, Seetharaman and Sichen [34] modified the relationship describing the activation energies into the following form:

$$
G^{*}=\sum_{i=1}^{n} X_{i} G_{i}^{*}+3 R T \sum_{i=1}^{n-1} \sum_{k=i+1}^{n} X_{i} X_{k}+\Delta G^{\prime}
$$

The authors of the report presented the calculations of both approaches; as it follows from their observations, the application of Eqs. 41 and 42 does not always give results that are in agreement with experimental data.

The model of Kozlov-Romanov-Petrov [35] also applies the mixing enthalpy of liquid solutions for the prediction of the viscosity, similar to the Moelwyn-Hughes model. It is represented with the following logarithmic equation:

$$
\ln (\eta)=\sum_{i=1}^{n} X_{i} \ln \left(\eta_{i}\right)-\frac{\Delta H^{\mathrm{m}}}{3 R T}
$$

A transformation of Eq. 43 gives the following expression, which describes the viscosity of alloys in the form of an exponential function:

$$
\eta=\exp \left[\sum_{i=1}^{n} X_{i} \ln \left(\eta_{i}\right)-\frac{\Delta H^{\mathrm{m}}}{3 R T}\right]
$$

In Eqs. 43 and 44, the viscosity of an alloy and its components is denoted by $\eta$ and $\eta_{i}$, mole fractions of components by $X_{i}$, the temperature by $T$, and the gas constant by $R$.

In 2004, Kaptay [36] proposed a modification of the Seetharaman and Sichen model (Eq. 42) for viscosity calculations; it consists of substituting the excess free energy into the equation of activation energy with the enthalpy of mixing multiplied by an $\alpha$ coefficient, which, according to the author, amounts to 0.155 to 0.015 , resulting in the following equation for the viscosity with the following form:

$$
\eta=\frac{h N_{0}}{\sum_{i=1}^{n} X_{i} V_{i}+\Delta V^{\mathrm{E}}} \exp \left(\frac{\sum_{i=1}^{n} X_{i} \Delta G_{i}^{*}-\alpha \Delta H^{\mathrm{m}}}{R T}\right)
$$

All the symbols in Eq. 45 have the same meaning as in the earlier presented models (Eqs. 38 to 44), while the new quantities, $V_{i}$ and $\Delta V^{\mathrm{E}}$, refer to the molar volume of alloy components and the excess molar volume of an $n$-component alloy. It should be noted that the molar volume included in the denominator of Eq. 45 is identical with the $M / \rho$ expression from the Seetharaman-Sichen model.

The presented models of viscosity calculations based on the thermodynamic properties were applied for the binary $\mathrm{Sn}-\mathrm{Ag}$ alloys for the same concentrations of metals such as those examined with the method of capillary flow and the RH technique. The equations describing the dependence of the viscosity on temperature applied in the calculations are reported in Table 5. 
Table 5 Dependences of the viscosity of liquid metals $\mathrm{Ag}$ and Sn on temperature

\begin{tabular}{lll}
\hline Metal & $\eta=A \exp \left(E_{\mathrm{a}} / R T\right)(\mathrm{mPa} \cdot \mathrm{s})$ & Author \\
\hline $\mathrm{Ag}$ & $0.5976 \exp (19137 /(R T))$ & Gebhardt et al. [12] \\
$\mathrm{Sn}$ & $0.4993 \exp (5675 /(R T))$ & This work \\
\hline
\end{tabular}

In the case of $\mathrm{Sn}$, the equation presented was derived based on three series of data: from the examination of the $\mathrm{Pb}-\mathrm{Sn}$ system [2], from the measurements using the $\mathrm{MC}$ method, and from the measurements using the RH method. The temperature dependences of the Ag viscosity were studied based on the values measured by Gebhardt et al. [12]. The excess free energy was calculated using the binary model as were the calculations of surface tension and $W_{i, j}$. The enthalpy of mixing applied in Eqs. 38, 44 , and 45 was calculated from the following equation:

$$
H^{\mathrm{m}}=G^{\mathrm{ex}}+T\left(-\frac{\mathrm{d} G^{\mathrm{ex}}}{\mathrm{d} T}\right)_{p}
$$

The thermodynamical parameters, describing binary interaction coefficients $W_{\mathrm{Ag}, \mathrm{Sn}}$ are the same as in Eq. 37, and the viscosities of pure $\mathrm{Sn}$ and $\mathrm{Ag}$ are presented in Table 5.

Modeling of the viscosity of $\mathrm{Ag}-\mathrm{Sn}$ alloys was conducted using five models and presented in Fig. 16. The lack of a universal model and the difficulty in modeling the viscosity are apparent. The best agreement between measured and calculated viscosity is given by the Seetharaman and Sichen model [34]. The data obtained from the Moelwyn-Hughes [32] model yield much higher values. One can notice that in the

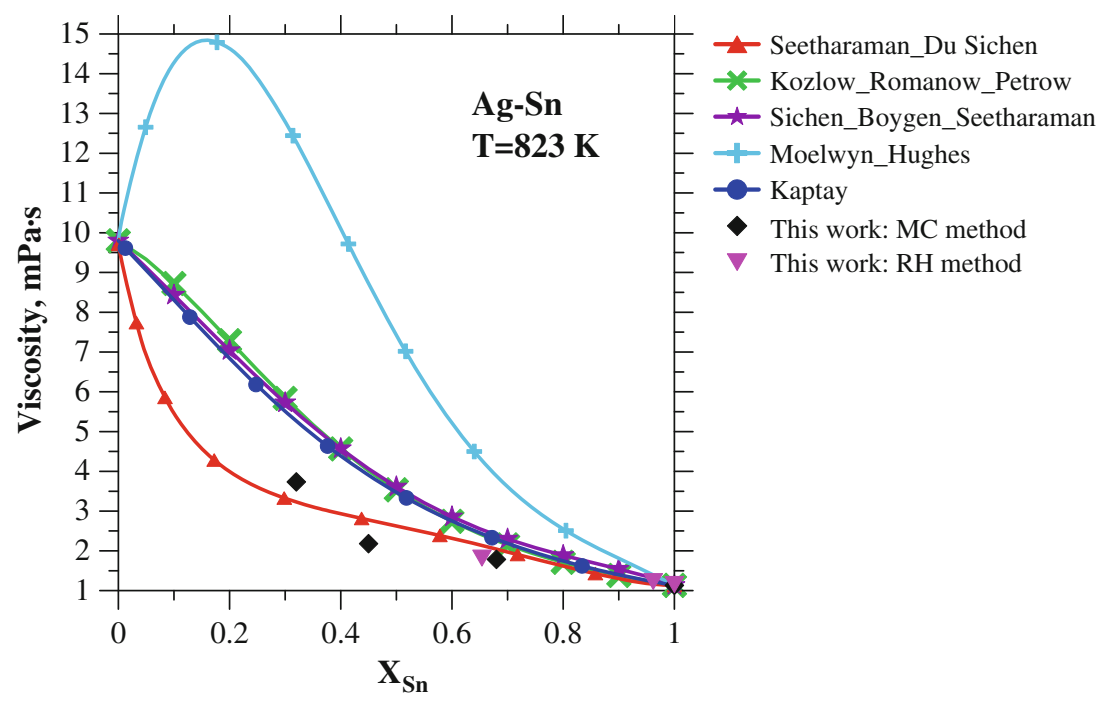

Fig. 16 Comparison of viscosity with models: Seetharaman and Du Sichen [34], Kozlov et al. [35], Sichen et al. [33], Moelwyn-Hughes [32], Kaptay [36], and this work: diamonds MC method, inverted triangle RH method 
Moelwyn-Hughes [32] model only the enthalpy of mixing is used for calculation of the viscosity and for such a case for alloys with a negative value of $H_{\mathrm{m}}$. The calculated viscosity will always be higher than that for the ideal solution $\left(G^{\mathrm{E}}\right.$ and $\left.H_{\mathrm{m}}=0\right)$; and for alloys with a positive value of $H_{\mathrm{m}}$, the viscosity will be lower than that for ideal solutions.

\section{Summary}

Calculations of the surface tension, density, and viscosity performed recently using the RH method were compared with those measured by using the MC method. A comparison between viscosity results using the MC method and $\mathrm{RH}$ method are presented. The values are in very good agreement, as is the case for density and surface tension from the RH method compared with previously published data of Gąsior et al. [2].

It is surprising that using a seemingly simple procedure of gravity flow from a crucible, one instrument/run generates values for three physical properties with good accuracy. It should be noted that the flow of fluid draining from a crucible in the RH method and analyzed here were for $R e>4000$. Experiments carried out using capillary flow were laminar with $R e<2000$. The RH method shows great promise to efficiently generate physical property data of alloys.

The measured results of surface tension show excellent agreement with the Butler model. For viscosity, the thermodynamic model proposed by Seetharaman and Sichen is in agreement with the experimental measurements of both the MC and RH methods.

Acknowledgments The authors wish to acknowledge the Natural Science and Engineering Research Council for funding the experimental work and analysis of the Edmonton effort. The authors from IMIM PAS wish to thank the Ministry of Science and Higher Education for financing the project on enlarging the SURDAT database.

Open Access This article is distributed under the terms of the Creative Commons Attribution Noncommercial License which permits any noncommercial use, distribution, and reproduction in any medium, provided the original author(s) and source are credited.

\section{References}

1. Z. Moser, W. Gąsior, J. Pstruś, J. Phase Equilib. 22, 254 (2001)

2. W. Gąsior, Z. Moser, J. Pstruś, M. Kucharski, Arch. Metall. 46, 23 (2001)

3. S.J. Roach, H. Henein, Can. Metall. Quart. 42, 175 (2003)

4. S.J. Roach, H. Henein, Metall. Mater. Trans. B 36, 667 (2005)

5. H. Henein, Can. Metall. Quart. 44, 261 (2004)

6. E. Rothwell, J. Inst. Met. 90, 389 (1962)

7. V.Z. Kisun'ko, I.A. Novokhatskii, A.Z. Beloborodov, Y.B. Bychkov, A.I. Pogorelov, Tsvetnte Metally (Non-Ferrous) 24, 84 (1983)

8. Z. Moser, W. Gąsior, A. Dębski, J. Pstruś, Database of Lead-free Soldering Materials (Institute of Metallurgy and Materials Science PAS, Krakow, 2007), ISBN 83-60768-01-3

9. E.E. Schpilrajn, W.A. Fomin, S.N. Scovorodko, G.F. Sokol, Isledowanie Wiazkosti Zidkich Metalov (Moskwa, Nauka, 1983)

10. T. Iida, R.I.L. Guthrie, The Physical Properties of Liquid Metals (Clarendon Press, Oxford, 1988), p. 77

11. R. Chhabra, D. Sheth, Z. Metallkd. 81, 264 (1990)

12. E. Gebhardt, M. Becker, E. Tragner, Z. Metallkd. 46, 379 (1955) 
13. K.C. Mills, Y.C. Su, Int. Mater. Rev. 51, 329 (2006)

14. D.R. Lide (ed.), CRC Handbook of Chemistry and Physics, 88th edn. (CRC Press, Boca Raton, FL, 2007)

15. R.R. Miller, Liquid Metals Handbook (Atomic Energy Commission and the Department of Navy, Washington, DC, 1952)

16. B.B. Alchagirov, A.M. Chochaeva, High Temp. 38, 44 (2000)

17. B.J. Keene, Int. Mater. Rev. 38, 157 (1993)

18. J. Lee, W. Shimoda, T. Tanaka, Mater. Trans. 45, 2864 (2004)

19. M. Kucharski, P. Fima, Monasch. Chem. 136, 1841 (2005)

20. J.A.V. Butler, Proc. R. Soc. Lond., Ser. A CXXXV, 348 (1932)

21. T. Tanaka, K. Hack, T. Iida, S. Hara, Z. Metallkd. 87, 380 (1996)

22. I. Ohnuma, X.J. Liu, K. Ishida, J. Electron. Mater. 28, 1164 (1998)

23. I. Ohnuma, X.J. Liu, Y. Inohana, K. Ishida, Z. Moser, W. Gąsior, J. Pstruś, W. Zakulski, in Proceedings of CALPHAD XXIX (Massachusetts Institute of Technology, Cambridge, MA, 2000), p. 15

24. M. Kucharski, Arch. Hut. 22, 181 (1977)

25. H. Ohtani, M. Miyashita, K. Ishida, J. Jpn. Inst. Met. 63, 685 (1999)

26. W. Gąsior, Z. Moser, J. Pstruś, J. Phase Equilib. 24, 504 (2003)

27. W. Gąsior, J. Pstruś, Z. Moser, A. Krzyżak, K. Fitzner, J. Phase Equilib. 24, 40 (2003)

28. P.E. Berthou, R. Tougas, Metall. Trans. 1, 2978 (1970)

29. J. Pstruś, Physico-Chemical Properties of New Solder Alloys on Example of Sn-Zn-In System, Ph.D. Thesis, Krakow, 2008

30. W.F. Gale, T.C. Totemeier (eds.), Smithells Metals Reference Book (Elsevier, Butterworth-Heinemann, Oxford, 2004)

31. I. Kaban, S. Mhiaoui, W. Hoyer, J.-G. Gasser, J. Phys.: Condens. Matter 17, 7867 (2005)

32. E.A. Moelwyn-Hughes, Phys. Chem. 434 (1970)

33. D. Sichen, J. Bygdén, S. Seetharaman, Metall. Mater. Trans. B 25, 519 (1994)

34. S. Seetharaman, D. Sichen, Metall. Mater. Trans. B 25, 589 (1994)

35. L.Y. Kozlov, L.M. Romanov, N.N. Petrov, Izv. Vuzov. Chernaya Metall. 3, 7 (1983)

36. G. Kaptay, in Proceeedings of MicroCAD 2003, International Conference Section: Metallurgy (University of Miskolc, Hungary, 2003), p. 23 